\title{
Evolução das Concepções de Futuros Professores sobre a Natureza e as Formas de Conhecer as Idéias dos Alunos
}

\author{
Evolution of pre-service teachers' conceptions in \\ relation to ways to consider and to get the students' ideas.
}

\author{
João Batista Siqueira Harres \\ Michelle Camara Pizzato \\ Ana Paula Sebastiany \\ Flaviane Predebon \\ Magda Cristiane Fonseca
}

\begin{abstract}
Resumo
Neste trabalho, analisamos a evolução das concepções de futuros professores em relação às formas de acessar e considerar as idéias dos alunos. A investigação tem por contexto uma disciplina do primeiro ano de um curso de licenciatura que forma professores para as disciplinas de física, química e matemática, estruturado de modo a favorecer, desde o início do curso, uma aproximação à futura prática docente. As análises envolveram a consideração da produção coletiva de três grupos de alunos da disciplina em contraste com uma hipótese de progressão dessas concepções. Os resultados indicam a presença de diferentes níveis de associação entre as concepções explicitadas e a sua aplicação.

Palavras-chave: formação de professores, idéias dos alunos, concepções e práticas docentes, desenvolvimento profissional.
\end{abstract}

\section{Abstract}

This work analyses the evolution of pre-service teachers' conceptions in relation to ways to get and to consider of the students' ideas. The research has for context a subject of a first year of science teacher program aiming at, since its beginning, the contact with the future teaching. The analyses consider the production of a three group of students in relation to a development conceptions' theory. The results indicate the existence of a different levels of the conceptions and its practice.

Keywords: teachers' education, students' ideas, theoretic and practical teaching, professional development. 


\section{Introdução}

Nos últimos anos, muitas investigações evidenciaram que no âmbito escolar, em contextos culturais e sociais muito diferentes, a formas de atuação docente são resistentes à mudança e à inovação. Existem muitas causas que explicam as razões desta resistência. Como formadores de professores, vimos investigando como determinadas concepções dos professores estão relacionadas com este problema. De modo geral, podemos dizer que os professores não são facilmente permeáveis às novas propostas uma vez que possuem concepções explícitas e implícitas sobre o ensino e a aprendizagem, coerentes com as tradições curriculares e com as características do contexto onde trabalham e que atuam, portanto, como obstáculos internos para a mudança e a inovação (Joram e Gabriele, 1998).

Em geral, este pensamento docente de "sentido comum" (Furió, 1994) se reforça durante a licenciatura por um processo tácito de impregnação ambiental no qual está ausente a reflexão consciente e argumentada, uma vez que a sua educação escolar anterior também se dá nesta mesma tradição. Assim, as crenças e rotinas já interiorizadas acabam se superpondo ao conhecimento disciplinar academicista, fragmentado e descontextualizado. Enfim, a socialização e a transmissão da cultura relacionada à prática profissional se constrói através de processos extraacadêmicos, ocultos e muito resistentes à mudança. De modo que a formação inicial não provoca a ruptura epistemológica e didática necessária para que emerja um conhecimento realmente profissionalizado e crítico.

De fato, as pesquisas sobre o conhecimento profissional dos professores indicam a presença majoritária de uma visão em que o ensino é concebido como um processo de transmissão direta de conteúdos, tomados como verdades absolutas e considerados como único referente para a programação. Ao mesmo tempo, a aprendizagem é concebida como a incorporação formal e mecânica destes conteúdos na mente dos alunos (Porlán e Rivero, 1998; Hewson e outros, 1999).

Acreditando que a formação inicial tem um papel preponderante na construção e evolução destas concepções, pensamos que ela deveria permitir a integração de maneira satisfatória entre os conhecimentos teóricos e aqueles baseados na experiência. Aliás, este é o espírito das recentes diretrizes emanadas pelo MEC quanto aos currículos dos cursos de licenciatura, o que indica que a situação descrita acima ainda é a mais comum. Nesse sentido, acreditamos em modelos formativos nos quais os futuros professores aprendam a questionar suas concepções e suas práticas relacionadas aos problemas curriculares fundamentais (o que ensinar e para quê, que tarefas utilizar na sala de aula, como fazer um acompanhamento da evolução do aprendizado dos alunos, etc.) e aprendam a estruturar e a implementar estas mudanças (Harres, 1999). 
Enfim, seguimos a hipótese de Hewson e outros (1999) de que quando os futuros professores são orientados em direção a processos de reconstrução crítica da conduta docente majoritária e do saber implícito que o sustenta (o modelo tradicional de ensino), submetendo-os a um contraste significativo e funcional com conhecimentos teóricos e experiências coerentes com os resultados da investigação educativa, é possível que surjam modelos didáticos mais conscientes, complexos e avançados capazes de sustentar uma prática inovadora e realmente profissionalizada.

\section{Metodologia}

\section{Delineamento do problema}

Em todo processo formativo (seja de alunos ou de professores), o conhecimento (científico ou profissional) não atua sobre uma mente (didática, no caso dos professores) "em branco" (Porlán e Rivero, 1998). Neste sentido, Joram e Gabriele (1998), por exemplo, concluíram que os professores apresentam idéias sobre ensino e aprendizagem antes de iniciar seu processo de formação. Essas idéias pedagógicas prévias estão muito arraigadas de modo que elas ou servirão de base para a interpretação da nova informação ou serão sérios obstáculos para a intenção formativa de implementar inovações em sala de aula (Azcárate, Martín del Pozo e Rivero, 2000). Portanto, os processos de formação inicial devem estar orientados para uma mudança gradativa desse conhecimento, partindo do conhecimento profissional prévio dos futuros professores, pois somente assim será possível favorecer que estes, por sua vez, possam também adotar posturas de maior consideração do conhecimento prévio dos seus alunos.

O contexto desta investigação situa-se no curso de Licenciatura Plena em Ciências Exatas, com habilitação integrada em Física, Química e Matemática da UNIVATES - Centro Universitário, em Lajeado/RS. Além da integração inédita de habilitações, o curso inova na vinculação entre teoria e prática na formação profissional, pois já nos primeiros semestres aparecem quatro disciplinas que fazem o papel de promotoras dos primeiros passos da evolução das concepções didáticas, denominadas de Laboratório de Ensino de Ciências Exatas. Essas disciplinas, distintas em sua natureza dos estágios supervisionados, das metodologias de ensino ou das disciplinas instrumentais, buscam oportunizar os primeiros passos do futuro professor em direção a uma postura reflexiva, crítica, aberta à mudança e em permanente evolução profissional. Esse objetivo é implementado através de situações e problemas significativos para os professores ou, como denominamos, Problemas Práticos Profissionais - PPPs (Harres e Pizzato, 2003). Segundo Azcárate e outros (2000), os PPPs podem ser entendidos como todas aquelas situações relacionadas com a 
realidade escolar e com a prática profissional que geram algum tipo de incerteza e para as quais não existe uma resposta única e rotineira.

Neste trabalho, analisamos o desenvolvimento das concepções de futuros professores cursando a disciplina de Laboratório de Ensino de Ciências Exatas II, estruturadas em torno a dois PPPS: Que sabemos sobre o que sabem os alunos sobre as Ciências Exatas? Como investigar o que sabem os alunos sobre as Ciências Exatas? A escolha destes PPPs deve-se ao fato de que o reconhecimento e a utilização didática das idéias dos alunos é uma das características que mais identifica um ensino construtivista, constituindo-se, portanto, em um aspecto do conhecimento profissional dos professores com alto poder formativo (García e Porlán, 2000).

As idéias dos alunos, como explicam Giordan e Vecchi (1995) não devem ser interpretadas unicamente como coleções de informações passadas ou como elementos de uma reserva informativa. Correspondem, isso sim, a uma mobilização do adquirido para efetuar uma explicação, uma previsão, ou uma ação simulada ou real. Durante esta mobilização, a pessoa, partindo de sua experiência, constrói uma rede de análise da realidade que lhe permitirá compreender o mundo que a rodeia, afrontar novos problemas, interpretar situações novas, etc. As idéias dos alunos, portanto, situam-se no centro dos problemas de aprendizagem, pois participam no jogo de relações existentes entre as informações de que dispõe um indivíduo e aquelas com as quais vai se encontrar ao longo de sua existência, e serão a base a partir da qual se elaboram seus novos saberes e suas condutas futuras.

Porém, apesar do relativo consenso de que o aluno não pode ser considerado uma tábua rasa e que isso modifica o modo de encarar o processo de ensino e aprendizagem, raras são as investigações nas quais a consideração das idéias dos alunos componham as crenças profissionais dos professores (López, 1999). E mesmo nestas investigações, as concepções dos alunos são tomadas pelos professores como inimigos que devem ser reprimidos ou superados, como se fossem erros de pensamento que devessem ser anulados e substituídos por outros novos (Giordan e Vecchi, 1995). Por isso, segundo Roth (1987) "a tarefa mais difícil na formação de professores é ajudar os professores a compreender o significado [dos] conceitos 'errôneos' e mudar a maneira geral de conceber (...) a aprendizagem das ciências" (p.47).

Sendo assim, nos propusemos a investigar qual é a evolução das concepções dos futuros professores sobre a natureza e a forma de conhecer as idéias dos alunos durante um processo formativo investigativo, e dentro deste problema, conhecer melhor as respostas às perguntas:

a) Quais as características dos questionários que os futuros professores utilizam para explicitar as idéias dos alunos?

b) Existe coerência entre as concepções dos futuros professores sobre natureza das idéias dos alunos e as formas propostas para conhecê-las? 
c) A estratégia formativa investigada promove uma evolução inicial das concepções dos futuros professores tanto sobre a natureza quanto sobre a forma de conhecer as idéias dos alunos?

\section{Marco de referência}

Para Porlán e Rivero (1998), a formação de professores deve envolver um processo de investigação apoiado no estabelecimento de hipóteses de progressão que partam das concepções mais freqüentes em direção a possíveis níveis de formulação de progressiva complexidade para a superação daqueles obstáculos e dificuldades que os professores podem apresentar em seu processo de aprendizagem. Neste sentido, alguns trabalhos mostram as relações existentes entre concepções epistemológicas, sobre aprendizagem e sobre a natureza das idéias dos alunos de acordo com o nível de complexidade destas concepções (Hashweh, 1996; García, 1999).

A partir disso, propusemos uma estrutura teórica para o desenvolvimento profissional das concepções dos futuros professores que apresenta duas características centrais. De um lado, um caráter evolutivo do desenvolvimento profissional docente e, de outro, um caráter integrador das concepções epistemológicas com as concepções sobre a aprendizagem (Harres e outros, 2003), sintetizadas na Tabela 1.

Tabela 1.

\section{Nível Concepções sobre Aprendizagem Concepções Epistemológicas}

\begin{tabular}{|l|l|l|}
\hline Inicial esperado & Receptiva simples & Racionalismo absolutista \\
\hline Intermediário & Construtivista reducionista & Empirismo moderado \\
\hline $\begin{array}{l}\text { Desejável } \\
\text { a curto prazo }\end{array}$ & Construtivista não reducionista & Empirismo sofisticado \\
\hline $\begin{array}{l}\text { Desejável } \\
\text { a longo prazo }\end{array}$ & Construtivista complexa & Evolucionismo construtivista \\
\hline
\end{tabular}

Quanto ao caráter evolutivo, nossa estrutura do desenvolvimento profissional esperado é gradual. Como indicam os resultados encontrados por diversas pesquisas, como as de Hewson e outros (1999), por exemplo, é pouco provável que professores, mesmo envolvidos em processos muito inovadores de formação, apresentem já ao final da graduação um nível de desenvolvimento profissional avançado. Assim, estruturamos uma perspectiva teórica 
orientadora da evolução profissional que compreende dois níveis intermediários entre o conhecimento profissional majoritário e dominante (inicial esperado) e o conhecimento profissional desejável a longo prazo.

O nível considerado como passível de ser alcançado ao final da licenciatura (desejável a curto prazo) corresponderia a uma situação em que determinadas concepções e vivências estariam razoavelmente explicitadas e fundamentadas de modo a ser possível prever que, havendo continuidade na caminhada reflexiva, poder-se-ia esperar que, a médio ou longo prazo, o professor alcançasse o nível desejável. Em outras palavras, haveria algumas etapas a serem vividas na licenciatura que seriam altamente potentes como base para um desenvolvimento profissional permanente no futuro.

Como acréscimo à teoria de desenvolvimento profissional proposta pelo grupo IRES (Porlán e Rivero, 1998), incluímos um nível intermediário entre o de partida e o desejável a curto prazo. Este nível (intermediário) seria coerente com o fato de que as vivências altamente significativas que temos proporcionado aos nossos futuros professores, logo no início da licenciatura, tem revelado uma evolução rápida desde as concepções dominantes no ensino em direção a concepções mais avançadas mesmo que ainda não acompanhadas de estratégias e fundamentos conceituais plenamente coerentes com estes ideais (Harres e outros, 2001 e 2004).

Quanto ao caráter integrador, vimos identificando que níveis de evolução entre as concepções relativas à aprendizagem e as concepções epistemológicas seriam coerentes com a perspectiva evolutiva comentada anteriormente e, ao mesmo tempo, com a inter-relação inexorável entre uma e outra no contexto escolar. Do ponto de vista da aprendizagem, adaptamos a hipótese de progressão proposta por García e Porlán (2000) baseada na consideração ou não da interação entre as idéias dos alunos e aquelas a serem aprendidos. Do ponto de vista epistemológico, adaptamos a perspectiva evolutiva das concepções sobre a natureza do conhecimento desenvolvida por Harres (1999), relacionada à consideração da existência ou não de verdades absolutas e das influências contextuais na construção do conhecimento. Os detalhes sobre cada um dos níveis desta hipótese e os dados que fundamentam sua produção estão explicitados em Harres e outros (2003).

Tendo em conta estes pressupostos, consideramos que as concepções sobre a natureza e as formas de conhecer as idéias dos alunos podem apresentar características associadas aos níveis recém citados. Esta associação reflete-se em uma estrutura hipotética evolutiva através da qual se acredita que os futuros professores possam evoluir. Construída conjuntamente com investigadores do grupo DIE (Didática e Investigação Escolar) da Universidade de Sevilha (Porlán e Martín, 2002), e ainda em fase de consolidação, tal estrutura apresenta três níveis que servem de 
orientação para a avaliação das atividades formativas: inicial esperado, de transição e desejável a curto prazo.

Com esta estrutura, pretende-se, de um lado, analisar a evolução das concepções dos futuros professores quanto à forma de conhecer e acessar as idéias dos alunos e, de outro lado, avaliar as atividades formativas, em uma interação dialética entre dados empíricos e perspectivas teórica. Buscando uma interação entre teoria e prática durante o processo formativo, duas categorias são consideradas. Uma delas é de dimensão teórica: as concepções dos futuros professores sobre a natureza das idéias dos alunos; e a outra é de dimensão prática: a proposição de um instrumento, na forma de um questionário, a ser utilizado para detectar as idéias dos alunos.

No nível inicial, cuja concepção epistemológica absolutista está associada a uma concepção não construtivista da aprendizagem, o futuro professor investiga o que o aluno sabe tomando como referência o conhecimento científico considerando que é esse o conhecimento que o aluno deve aprender, de forma linear. Perguntas nesse nível favorecem respostas automáticas (recordar, preencher, assinalar, etc.), fechadas e acadêmicas, induzindo o aluno a responder aquilo que acredita que o professor quer ouvir, havendo assim, pequena chance de que $o$ aluno expresse o que realmente pensa sobre o assunto.

Já no nível desejável, a concepção epistemológica é construtivista-evolutiva, uma vez que considera a existência de outras fontes do conhecimento (cotidiano, cultural, ideológico, etc.) tão válidas quanto o conhecimento científico. Perguntas nesse nível favorecem respostas elaboradas (relacionar, refletir, explicar, etc.), abertas e do entendimento do cotidiano, induzindo o aluno a explicitar suas idéias de forma mais voluntária.

Como nosso objetivo não é apenas estabelecer as relações entre as concepções sobre a natureza e a forma de conhecer as idéias dos alunos, mas também os níveis evolutivos em que estas relações se manifestam, consideramos a existência de um nível de transição entre o inicial e o desejável, identificado pela presença mesclada de características de ambos os níveis. 0 detalhamento sobre os níveis evolutivos considerados é apresentado mais adiante (Tabelas 3 e 4), juntamente com os dados encontrados.

\section{Desenvolvimento da investigação}

A coleta de dados incidiu sobre a produção coletiva de três grupos participantes da edição de 2004 da disciplina Laboratório de Ensino de Ciências Exatas II, escolhidos a partir de uma análise prévia geral buscando identificar diferentes trajetórias evolutivas. O Tabela 2 descreve os momentos de coleta de dados em função da metodologia formativa aplicada. 
Tabela 2: momentos da investigação

\begin{tabular}{|l|l|} 
Momentos & Ações \\
\hline 1 & $\begin{array}{l}\text { Elaboração da primeira versão do questionário sem consultar nenhuma informação } \\
\text { externa. Cada grupo elaborou a primeira versão de um questionário para explicitar as } \\
\text { idéias dos alunos sobre algum conteúdo escolhido previamente. }\end{array}$ \\
\hline 2 & $\begin{array}{l}\text { Respostas ao primeiro guia de reflexão da disciplina (anexo), elaboradas após a leitura e } \\
\text { discussão de artigos que tratam de questionários e idéias dos alunos, e do livro “Cómo } \\
\text { trabajar com las ideas de los alumnos" (Cubero, 2000). }\end{array}$ \\
\hline 3 & $\begin{array}{l}\text { Elaboração da segunda versão do questionário, considerando as atividades anteriores e } \\
\text { podendo utilizar toda informação desejada. }\end{array}$ \\
\hline 4 & $\begin{array}{l}\text { Respostas a outros guias de reflexão elaborados nas atividades seguintes, tais como } \\
\text { seleção e organização de conteúdos e elaboração de um plano de ensino, nas quais } \\
\text { podem se manifestar outras idéias a respeito da dimensão teórica. }\end{array}$ \\
\hline
\end{tabular}

As concepções sobre a natureza das idéias dos alunos (dimensão teórica) foram analisadas e classificadas de acordo com os níveis evolutivos propostos no marco teórico (Tabela 3) e a percepção da evolução destas concepções foi analisada pela comparação dos resultados obtidos nos Momentos 2 e 4 . As concepções sobre a forma de conhecer as idéias dos alunos (dimensão prática) foram analisadas através da classificação das perguntas das duas versões de questionários elaboradas de acordo com as categorias e níveis apresentados anteriormente em nossa hipótese de classificação das características de um questionário para explicitar idéias prévias (Tabela 4). A análise da evolução destas concepções se deu pela comparação dos resultados obtidos na análise das duas versões (Momentos 1 e 3 ).

\section{Análise dos Resultados}

\section{Resultados Encontrados quanto à dimensão teórica}

Em relação à perspectiva teórica desta dimensão (Tabela 3), as respostas dadas ao guia de reflexão (Momento 2), detalhada a seguir, indicam uma aproximação das idéias dos três grupos com o Nível 2. 
Tabela 3: níveis de evolução em relação à natureza das idéias dos alunos

Nível
\begin{tabular}{|l|l|l|}
\multicolumn{2}{l}{ Status } & Natureza das idéias dos alunos \\
\hline 1 & Inicial Esperado & $\begin{array}{l}\text { As idéias dos alunos se identificam com aquilo que recordam do ensino } \\
\text { recebido. As idéias espontâneas não são consideradas }\end{array}$ \\
\hline 2 & De Transição & $\begin{array}{l}\text { As idéias dos alunos se diferenciam entre idéias acadêmicas e as } \\
\text { espontâneas, apresentando estas últimas componentes comuns e } \\
\text { idiossincráticos e com certas características (resistências, errôneas, } \\
\text { etc.). }\end{array}$ \\
\hline 3 & $\begin{array}{l}\text { Desejável a } \\
\text { Curto Prazo }\end{array}$ & $\begin{array}{l}\text { conhecias espontâneas são conhecimentos alternativos ao } \\
\text { da vida e, por isso, sua relevância epistêmica, isto é, sua implicação na } \\
\text { concepção de aprendizagem de referência (complexificação das idéias } \\
\text { dos alunos). }\end{array}$ \\
\hline
\end{tabular}

Em relação à utilidade de conhecer as idéias dos alunos anteriormente ao planejamento (Pergunta 1), as respostas dos grupos, em geral, situaram-se próxima a uma posição de que é importante conhecer as idéias dos alunos para avaliar de que ponto partir em relação aos conteúdos: "para que o professor saiba como agir, como solucionar as dúvidas dos alunos" (Grupo A); "conhecendo suas idéias o professor poderá conduzir o estudo a partir do que o aluno conhece sobre o assunto" (Grupo B); "a utilidade é conhecer o ponto de partida da abordagem do conteúdo a ser estudado, grau ou nível de conhecimento da turma" (Grupo C). Estas frases parecem expressar uma concepção de que a partir das idéias dos alunos há um caminho único em direção à aprendizagem dos conteúdos escolares, o que justificaria a necessidade de identificação "precisa" do ponto de onde partir, tomando, enfim, as idéias dos alunos como um pré-requisito para a aprendizagem dos novos conteúdos.

Quanto ao uso da expressão "idéias dos alunos" (Pergunta 2), de um lado, os licenciandos usam expressões como "o que realmente os alunos sabem sobre determinado assunto" (Grupo B). De outro lado, em uma perspectiva aparentemente menos conteudista, aparecem expressões como "concepções de mundo e de aprendizagem" (Grupo A) e "concepções e deduções do seu cotidiano" (Grupo C).

Em relação a existência de dois tipos de idéias - escolares e espontâneas (Pergunta 3), as respostas centram-se na necessidade de aproximação entre idéias espontâneas e conhecimentos escolares: "Muitas vezes o que é ensinado na escola não se relaciona com o dia-a-dia [idéias 
espontâneas], deixando os alunos com dúvidas e contradições ao que vivenciam no seu dia-a-dia" (Grupo A); "Pensamos que existe uma distância muito grande entre a escola e o cotidiano, causando nos alunos dois mundos de saberes diferentes." (Grupo C).; "Muitas vezes os alunos são levados a pensar o que a escola pensa, deixando de lado suas próprias idéias. Às vezes, os alunos respondem o que a professora quer saber para passar de ano, e não aquilo que acreditam ser certo."(Grupo B).

No Momento 4 da investigação, os Grupos A e B foram ainda classificados no Nível 2. O Grupo A não apresentou, nas atividades seguintes, nenhuma indicação que pudesse ser identificada com as características do nível superior da dimensão teórica. Já o Grupo B, em uma atividade que tratava da importância de analisar as idéias dos alunos, comentou que "(...) os alunos trazem uma bagagem ampla. No entanto, às vezes, não é o correto o que eles pensam. Então, a partir de uma investigação, o professor consegue sentir segurança e seguir em frente, construindo o correto", como a sustentar que a diferença entre as idéias acadêmicas e as espontâneas está em que estas últimas podem ser errôneas.

O Grupo C, apresentando evolução em sua concepção inicial, expressou que “(...) [o professor poderia] construir um saber coerente com o que já existe no senso comum dos alunos. Esse senso comum pode ser acrescido de conhecimento, alterado ou até posto à prova para que seja derrubado, caso seja equivocado". Esta frase parece indicar uma valorização da consideração das idéias dos alunos em termos da sua relevância epistemológica, uma vez que essas idéias seriam conhecimentos alternativos ao conhecimento disciplinar.

\section{Resultados encontrados quanto à dimensão prática (Momentos 1 e 3)}

Em relação às características consideradas na análise desta dimensão (Tabela 4), os Grupos A e B apresentaram questionários muito diferentes entre si e que não sofreram modificações do Momento 1 para o Momento 3.

Tabela 4: níveis de evolução em relação

às características dos questionários

\begin{tabular}{|c|c|c|c|}
\hline Categoria & Nível Inicial (1) & Nível de Transição (2) & Nível Desejável (3) \\
\hline $\begin{array}{l}\text { Linguagem } \\
\text { utilizada }\end{array}$ & $\begin{array}{l}\text { Linguagem não } \\
\text { apropriada (inacessível, } \\
\text { adulta, técnica, acadêmica) }\end{array}$ & $\begin{array}{l}\text { Mescla de uma apropriada } \\
\text { para a idade dos alunos com } \\
\text { outra que não o é }\end{array}$ & $\begin{array}{l}\text { Apropriada para a } \\
\text { idade dos alunos } \\
\text { (acessível, próxima, } \\
\text { cotidiana) }\end{array}$ \\
\hline
\end{tabular}




\begin{tabular}{|c|c|c|c|}
\hline Categoria & Nível Inicial (1) & Nível de Transição (2) & Nível Desejável (3) \\
\hline $\begin{array}{l}\text { Forma de } \\
\text { perguntar }\end{array}$ & Direta & $\begin{array}{l}\text { Misturam-se perguntas } \\
\text { diretas e indiretas }\end{array}$ & $\begin{array}{l}\text { Indireta (através de } \\
\text { situações, exemplos, } \\
\text { imagens, etc.) }\end{array}$ \\
\hline $\begin{array}{l}\text { Conteúdo da } \\
\text { pergunta }\end{array}$ & $\begin{array}{l}\text { O conteúdo se relaciona } \\
\text { com dados, nomes, } \\
\text { definições, etc. }\end{array}$ & $\begin{array}{l}\text { O conteúdo se relaciona } \\
\text { com dados, nomes, } \\
\text { definições, etc. E com } \\
\text { significados. }\end{array}$ & $\begin{array}{l}\text { O conteúdo das } \\
\text { perguntas se } \\
\text { relaciona com } \\
\text { significados }\end{array}$ \\
\hline $\begin{array}{l}\text { Nível de } \\
\text { organização da } \\
\text { realidade a } \\
\text { que se refere a } \\
\text { pergunta }\end{array}$ & $\begin{array}{l}\text { Macrocosmos e } \\
\text { microcosmos e o não } \\
\text { perceptível (de forma direta } \\
\text { ou através dos meios de } \\
\text { comunicação) }\end{array}$ & $\begin{array}{l}\text { Mesclam-se mesocosmos e } \\
\text { o não diretamente } \\
\text { perceptível pelo aluno }\end{array}$ & $\begin{array}{l}\text { Mesocosmos e de } \\
\text { percepção habitual } \\
\text { e/ou de relação do } \\
\text { mesocosmos com os } \\
\text { níves mais próximos } \\
\text { do micro e do } \\
\text { macrocosmos. }\end{array}$ \\
\hline $\begin{array}{l}\text { Resposta } \\
\text { buscada }\end{array}$ & $\begin{array}{l}\text { Predominantemente } \\
\text { fechada }\end{array}$ & $\begin{array}{l}\text { Perguntas abertas e } \\
\text { fechadas }\end{array}$ & $\begin{array}{l}\text { Predominantemente } \\
\text { aberta }\end{array}$ \\
\hline $\begin{array}{l}\text { Recurso } \\
\text { comunicativo }\end{array}$ & $\begin{array}{l}\text { Somente texto e muitas } \\
\text { perguntas }\end{array}$ & $\begin{array}{l}\text { Somente texto e um número } \\
\text { razoável de perguntas ou } \\
\text { com desenhos, pessoas, etc. } \\
\text { e muitas perguntas }\end{array}$ & $\begin{array}{l}\text { textos, desenhos, } \\
\text { esquemas, etc. e } \\
\text { com um número } \\
\text { razoável de } \\
\text { perguntas }\end{array}$ \\
\hline $\begin{array}{l}\text { Demanda } \\
\text { intelectual que } \\
\text { a resposta } \\
\text { requer }\end{array}$ & $\begin{array}{l}\text { Respostas pouco elaboradas } \\
\text { (recordar, preencher, } \\
\text { assinalar, etc.) }\end{array}$ & $\begin{array}{l}\text { Se misturam perguntas que } \\
\text { requerem respostas } \\
\text { elaboradas com outras que } \\
\text { requerem pouca elaboração }\end{array}$ & $\begin{array}{l}\text { Respostas } \\
\text { elaboradas } \\
\text { (relacionar, refletir, } \\
\text { explicar, etc.) }\end{array}$ \\
\hline $\begin{array}{l}\text { Seleção e } \\
\text { organização } \\
\text { das perguntas }\end{array}$ & $\begin{array}{l}\text { Sem critérios de seleção e } \\
\text { organização explícitos }\end{array}$ & $\begin{array}{l}\text { Se manifestam critérios de } \\
\text { seleção diversos e uma } \\
\text { organização explícita }\end{array}$ & $\begin{array}{l}\text { Se manifestam } \\
\text { critérios de seleção } \\
\text { diversos e uma } \\
\text { organização } \\
\text { explícita }\end{array}$ \\
\hline
\end{tabular}

Segundo nossa análise, o Grupo A propôs um questionário que se identifica com um nível intermediário entre o de transição (Nível 2) e o desejável (Nível 3). Em seu questionário, se 
destacam avanços em relação à linguagem utilizada, ao conteúdo das perguntas, ao nível de organização da realidade a que se referem às perguntas, à resposta buscada e à demanda intelectual que a resposta requer. Já o questionário do Grupo B não se apresentou tão evoluído, com fortes carências na linguagem e na forma de perguntar, ao mesmo tempo em que nenhuma das demais características se identificava com o nível desejável e, por isso, o classificamos com estando associado ao Nível 2. O Tabela 5 mostra os questionários destes dois grupos.

Tabela 5: questionários dos Grupos A e B.

\section{Questionário Grupo A}

\begin{tabular}{|c|c|}
\hline Por que as coisas se movimentam? & $\begin{array}{l}\text { Observe a figura: } \\
\text { Como se chama a parte pintada? }\end{array}$ \\
\hline $\begin{array}{l}\text { Se eu chutar uma bola, o que acontece } \\
\text { com ela? Por quê? }\end{array}$ & $\begin{array}{l}\text { Imagine a barra de chocolate } \\
\text { onde a parte pintada já foi comida: } \\
\text { Quantas partes tinham ao todo? } \\
\text { Quantas foram comidas? }\end{array}$ \\
\hline $\begin{array}{l}\text { Se você subir em uma cadeira e pular } \\
\text { dela, o que acontece? Por quê? }\end{array}$ & $\begin{array}{l}\text { Imagine você juntando um meio de um círculo e dois } \\
\text { quartos do mesmo, o que teremos? }\end{array}$ \\
\hline $\begin{array}{l}\text { Você acha que se largarmos dois objetos } \\
\text { (uma bola e uma pedra) da mesma altura } \\
\text { e no momento, os dois chegam juntos ao } \\
\text { chão? Por quê? }\end{array}$ & O que vale mais: $1 / 2$ ou $1 / 10$ ? \\
\hline O que é gravidade para você? & O que você entende por fração? \\
\hline
\end{tabular}

O Grupo C modificou significativamente seu questionário inicial. Comparando as duas versões do questionário, podemos perceber que as modificações apontam para uma evolução desde o nível de transição (Nível 2) para um nível intermediário entre este e o desejável, ou seja, Nível 2,5. Quanto à linguagem, houve a incorporação de palavras mais cotidianas em algumas perguntas. Já as Questões 1 e 2 da primeira versão foram modificadas pela adição das palavras alimentos e líquidos, e pela omissão da expressão substâncias básicas, mais próxima de uma linguagem acadêmica, na Questão 1 da segunda versão. 
Outro aspecto que sofreu mudança diz respeito ao conteúdo de algumas questões na busca de respostas mais elaboradas pelos alunos. Como exemplo, podemos ressaltar a incorporação da Questão 2 na segunda versão, como uma tentativa de ir além da simples descrição de exemplos, como proposto nas Questões 1 e 2 da primeira versão. Já a Questão 5 da primeira versão, que incitava a respostas automáticas, dando a entender que haveria uma única resposta, foi substituída pela Questão 6, com mais chance de provocar uma resposta elaborada. Por último, cabe ressaltar a modificação da Questão 4 (primeira versão) na versão final (Questão 7), indicando uma mudança desde uma concepção mais conteudista ("seu conhecimento") em direção a uma concepção sobre as idéias dos alunos mais próxima do desejável ("o que você entende"). O Tabela 6 apresenta as duas versões elaboradas pelo Grupo C.

Tabela 6: primeira e segunda versões dos questionários do Grupo C.

\section{Primeira Versão (C1)}

1. Cite exemplos de substâncias ácidas no seu dia-a-dia.

2. Dê exemplos de substâncias ácidas e básicas
existentes no corpo humano

3. O que você entende por chuva ácida?

4. Descreva seu conhecimento sobre pH.

5. Pastilha de magnésia e leite de magnésia são que tipos de substâncias?

6. Por que a cal é usada na entrada de aviários?

7. qual o significado da aplicação de uréia ou
cal hidratada no tratamento do solo?

O Tabela 7 sintetiza a análise dos questionários dos três grupos segundo as características analisadas. A classificação de uma característica como sendo dos Níveis 1,5 ou 2,5 refere-se a estágios intermediários entre os níveis de evolução propostos.
1. Dê exemplos de alimentos, substâncias e ou líquidos ácidos que você encontra no seu dia-adia.

2. Descreva o que eles têm em comun.

3. O que você entende por chuva ácida?

4. Por que a cal é usada na entrada de aviários?

5. Para que finalidade a uréia é utilizada a uréia e a cal hidratada no tratamento do solo?

6. O que provoca a azia e a afta no corpo humano?

7. Escreva o que você entende por pH. 
Tabela 7: detalhamento dos níveis dos questionários segundo as características analisadas

\begin{tabular}{|l|l|l|l|l|}
\hline Característica / Grupo & A & B & C1 & C2 \\
\hline Linguagem utilizada & 2,5 & 1,5 & 2 & 2,5 \\
\hline Forma de perguntar & 2 & 1,5 & 2 & 2 \\
\hline Conteúdo das perguntas & 2,5 & 2 & 2,5 & 2,5 \\
\hline Nível de organização da realidade a que se referem as perguntas & 3 & 2 & 2 & 2,5 \\
\hline Respostas buscadas & 3 & 2,5 & 3 & 3 \\
\hline Recurso comunicativo & 2 & 2 & 2 & 2 \\
\hline Demanda intelectual que as respostas requerem & 2,5 & 2 & 2 & 2,5 \\
\hline Seleção e organização das perguntas & 2 & 2 & 1 & 3 \\
\hline Média & 2,4 & 1,9 & 2,1 & 2,5 \\
\hline
\end{tabular}

\section{Análise da evolução e considerações finais}

O Tabela 8 sintetiza a classificação dos grupos investigados nos quatro momentos de coleta de dados, de acordo com os níveis evolutivos apresentados, respectivamente, para as dimensões teórica e prática.

O Tabela 8 sintetiza a classificação dos grupos investigados nos quatro momentos de coleta de dados, de acordo com os níveis evolutivos apresentados, respectivamente, para as dimensões teórica e prática.

Tabela 8.

\begin{tabular}{|l|l|l|l|l|}
\cline { 2 - 5 } \multicolumn{1}{c|}{} & \multicolumn{2}{l|}{ Dimensão Teórica } & \multicolumn{2}{l|}{ Dimensão Prática } \\
\cline { 2 - 5 } \multicolumn{1}{c|}{} & Momento 2 & Momento 4 & Momento 1 & Momento 3 \\
\hline Grupo A & 2 & 2 & 2,5 & 2,5 \\
\hline Grupo B & 2 & 2 & 2 & 2 \\
\hline Grupo C & 2 & 3 & 2 & 2,5 \\
\hline
\end{tabular}

Analisando a Tabela 8, verifica-se que o Grupo A já partiu de um nível em que as idéias acadêmicas e espontâneas se diferenciam, portanto poder-se-ia afirmar que isto levou a que não visse necessidade de alterar substancialmente seu questionário inicial. O Grupo B partiu de um 
nível mais incipiente, porém parece que as atividades desenvolvidas permitiram uma evolução no sentido de diferenciação entre idéias acadêmicas e espontâneas. $O$ fato de ambos os questionários não terem sofrido evolução pode estar relacionado à não evolução nas concepções sobre a natureza das idéias dos alunos. Por sua vez, o Grupo $C$ apresentou evolução em ambas dimensões. O questionário sofreu modificações importantes e, concomitantemente, as suas concepções sobre a natureza das idéias dos alunos também evoluíram em direção ao nível desejável da consideração da relevância epistêmica destas idéias conforme identificado em outras atividades da disciplina.

Comparando os nossos resultados com outros trabalhos especialmente orientados para a consideração didática das idéias dos alunos, percebemos as mesmas dificuldades e obstáculos. López (1995), por exemplo, encontrou que nenhum dos dois sujeitos analisados em seu estudo de caso se encontrava no que corresponderia ao nosso nível desejável no final do processo formativo. Outros trabalhos também detectaram a identificação das idéias dos alunos com um organizador (espécie de pré-requisito) dos conteúdos (Jonhston, 1991), a dificuldade de planejar atividades orientadas para a evolução das idéias dos alunos apesar da consciência da sua importância (Hand e Treagust, 1994) ou, ainda, a presença de uma concepção epistemológica absolutista sobre o conhecimento como um impedimento a uma consideração mais construtivista da aprendizagem, tal como nossa hipótese de progressão supõe, ou seja, a superação da concepção das idéias dos alunos como um "erro a eliminar" (Hollon e outros, 1991).

Finalmente, o contraste entre nossa perspectiva teórica e os dados encontrados permite afirmar que a proposta formativa contribui para a evolução das concepções investigadas. No entanto, coerente com os resultados de trabalhos nesta linha, esta evolução e a inter-relação entre as dimensões teórica e prática está vinculada aos diferentes níveis de conhecimento inicial dos sujeitos investigados. Do ponto de vista teórico, os níveis propostos mostraram-se úteis na caracterização da evolução das concepções, ao mesmo tempo em que a análise dos dados permitiu um refinamento desta estrutura pela identificação de níveis intermediários aos inicialmente formulados. Isto favorecerá um aprimoramento da proposta formativa através de um melhor ajuste entre atividades e níveis reais de evolução e poderá colaborar também com um maior conhecimento da comunidade sobre a evolução das concepções e práticas de futuros professores, tema sobre o qual ainda existe, em nosso meio, carência de investigações de acompanhamento aprofundado e a longo prazo.

\section{Referências}

AZCÁRATE, P.; MARTÍN DEL POZO, R. E RIVERO, A. Los ámbitos de investigación profesional. In: Congreso Nacional de las Didácticas Específicas, 2000. p.1613-1623. 
CUBERO, R. Cómo trabajar com las ideas de los alumnos. Sevilha: Díada, 2000. 78p.

FURIÓ, C. Tendências actuales em la formación del profesorado de ciências. Enseñanza de las Ciencias, v.12, n.2, p.188-199, 1994.

GARCÍA, J.E. Las ideas de los alumnos. Cuadernos de Pedagogía, n.276, p.58-64, 1999.

GARCÍA, J.E.; PORLÁN, R. Ensino de ciências e prática docente: uma teoria do conhecimento profissional. In: HARRES, J.B.S. (org.). Ensino de ciências: Teoria e prática docente. Lajeado: UNIVATES Editora, 2000. p.7-42.

GIORDAN, A.; VECCHI, G. Los orígenes del saber. 2. ed. Sevilla: Díada, 1995.

GRUPO INVESTIGACIÓN EN LA ESCUELA Proyecto Curricular Investigación y Renovación Escolar (IRES). 4 volumes, versão provisional. Sevilla: Díada, 1991.

HAND, B.; TREAGUST, D.F. Teachers' thoughts about changing to constructivist teaching/learning approaches within junior secondary science classrooms. Journal of Education for Teaching, v.20, n.1, p.97-112, 1994.

HARRES, J.B.S. Concepções de professores sobre a natureza da ciência. 1999. Tese (Doutorado). Pontifícia Universidade Católica do Rio Grande do Sul, Porto Alegre.

HARRES, J.B.S. A evolução do conhecimento profissional de professores: o caso do conhecimento prévio sobre a forma da Terra. Caderno Catarinense de Ensino de Física, v.18, n.3, p.278-297, 2001.

HARRES, J.B.S.; HENZ, T.; ROCHA, L.B. O que pensam os professores sobre o que pensam os alunos. Uma pesquisa em diferentes estágios de formação no caso das concepções sobre a forma da Terra. Revista Brasileira de Pesquisa em Educação em Ciências, v.1, n.2, p.40-50, 2001.

HARRES, J.B.S.; PIZZATO, M.C. Laboratórios de ensino: investigando problemas práticos profissionais. In: Escola de Verão para Professores de Práticas de Ensino de Biologia, Física e Química, 6., Niterói, 2003.

HARRES, J.B.S.; PIZZATO, M.; HENZ, T.; WEBER, L. Uma hipótese de progressão do desenvolvimento profissional: análise de um caso na formação inicial de professores. In: Encontro Nacional de Pesquisa em Educação em Ciências, 4., Bauru, 2003.

HARRES, J.B.S.; PIZZATO, M.; FONSECA, M.C. HENZ, T. Evolução Inicial das concepções didáticas de futuros professores de ciências exatas. In: Encontro de Pesquisadores em Ensino de Física, 9., Jaboticatubas, 2004.

HASHWEH, M.Z. Effects of science teacher's epistemological beliefs in teaching. Journal of Research in Science Teaching, v.33, n.1, p.47-63, 1996. 
HEWSON, P.W; TABACHNICK, B.R.; ZEICHNER, K.M; LEMBERGER, J. Educating prospective teachers o biology: findings, limitations, and recomendations. Science Education, v.83, n.3, p.373-384, 1999.

HOLLON, R.E; ROTH, K.; ANDERSON, C.W. Science teachers' conceptions of teaching and learning. In: BROPHY, J. Advances on research on teaching, Nova lorque, v.2, p.145-185, 1991.

JOHNSTON, K. High school science teachers' conceptualisations of teaching and learning: theory and practice. European Journal of Teacher Education, v.14, n.1, p.65-78, 1991.

JORAM, E.; GABRIELE, A.J. Preservice teacher's prior beliefs: transforming obstacles into opportunities. Teaching and Teacher Education, v.14, n.2, p.175-191, 1998.

LÓPEZ, J.I.R. El conocimiento profesional de los profesores acerca de las concepciones de los alumnos. Dos estúdios de caso em la enseñanza y el aprendizaje de las ciencias. 1995. Tese (Doutorado) - Universidade de Sevilha, Espanha.

LÓPEZ, J.I.R. Conocimiento docente y práctica investigativa: el cambio hacia uma enseñanza centrada en el aprendizaje. Málaga: Aljibe, 1999.

PORLÁN, R.; RIVERO, A. El conocimiento de los profesores: uma proposta en el área de ciencias. Sevilla: Díada, 1998.

PORLÁN, R.; MARTíN, R.P. La formación Del profesorado em um contexto constructivista. In: Encuentro Iberoamericano sobre Investigación Básica em Educación em Ciencias, 1., Burgos (Espanha), 2002, p.81-92.

ROTH, K.J. Helping science teachers change: the critical role of teachers' knowledge about sicence and acience learning. In: Annual Meeting of the American Educational Research Association, Wshington, D.C., 1987. 


\section{Anexo}

Primeiro guia de reflexão da disciplina

Pergunta 1 - "Que utilidade tem conhecer as idéias dos alunos antes de planejar as aulas?"

Pergunta 2 - "Ao utilizar a expressão 'idéias dos alunos', a que estamos nos referindo exatamente?"

Pergunta 3 - Segundo alguns autores, os alunos têm em sua mente idéias que vem construindo com base nas suas experiências não escolares (idéias espontâneas) e, por outro lado, idéias que se identificam basicamente com o contexto escolar. O que você pensa a esse respeito?

João Batista Siqueira Harres

Michelle Camara Pizzato

Ana Paula Sebastiany

Flaviane Predebon

Magda Cristiane Fonseca

UNIVATES Centro Universitário, GPFP - Grupo de Pesquisa na Formação de Professores gpfp@univates.br 